\title{
Undulator systems for the TESLA X-FEL
}

\author{
J. Pflüger, M. Tischer, HASYLAB
}

\section{Introduction}

The undulator is the heart of any FEL. It provides the periodic magnetic field so that the FEL process can take place. SASE FEL's in the X-ray regime need undulators lengths in the order of $200 \mathrm{~m}$ and more Such devices cannot be built in one piece, but have to be subdivided into 'undulator segments'. Additional components like strong focusing quadrupoles, phase adjusters, beam correctors, position monitors etc. are needed as well. Together they form an 'undulator cell'. An undulator system is an array of many such cells. Fig. 1 shows a 3D view of an array of three cells which are part of a much larger system. The components of an undulator cell will be described in more detail in this contribution. In the preceding section the TESLA project and the FEL laboratory is presented. Table 1 summarizes the parameters of the undulator systems for the TESLA FEL. They were the results of an extensive evaluations./1-3/.

Five SASE FEL's are planned in total. Four of them, SASE1 through SASE4 are primary FEL's using the fresh TESLA electron beam. They produce linearly polarized light and operate primarily in $0.1 \mathrm{~nm}$ wavelength regime. There will be a secondary FEL, SASE5, which will be a helical one. It will use the spend beam of SASE3 and will operate in the soft X-ray regime at wavelength up to $2.5 \mathrm{~nm}$. In addition, there will be five spontaneous radiators, U1 through U5, which will use the spent electron beam of the remaining tree SASE FEL's. From the standpoint of undulator design there is no significant difference between SASE and spontaneous undulators. As can be seen in table 1 there will be only four different types of devices. This is a situation commonly found on small XUV synchrotron radiation (SR) sources. The difference is, however, the sheer length required by the SASE process. The length of a single X-FEL is comparable to or even larger than that of all undulators in a $3^{\text {rd }}$ generation X-ray machine. For example, the total ID length of the ESRF by November 2000 is $104 \mathrm{~m}$. Similar numbers hold for the other X-ray machines. In contrast the total magnetic length of the TESLA undulators is $1405 \mathrm{~m}$ (see table 1).

There has been a tremendous development of insertion device technology within the past 20 years when insertion devices came into use as intense sources of SR. Since then an enormous progress has been made in the design, construction and optimization of these devices. There are now well established techniques to produce insertion devices with properties which are very close to ideal. They have become state of the art. Consequently, for the undulator systems needed for the TESLA FEL's there will be no fundamental problem with the design and construction. The real innovative challenge is the construction of the immense number of undulator length in sufficient quality, in reasonable time and at reasonable cost. The plans for the TESLA FEL lab are briefly outlined for the 2000 Annual Report.

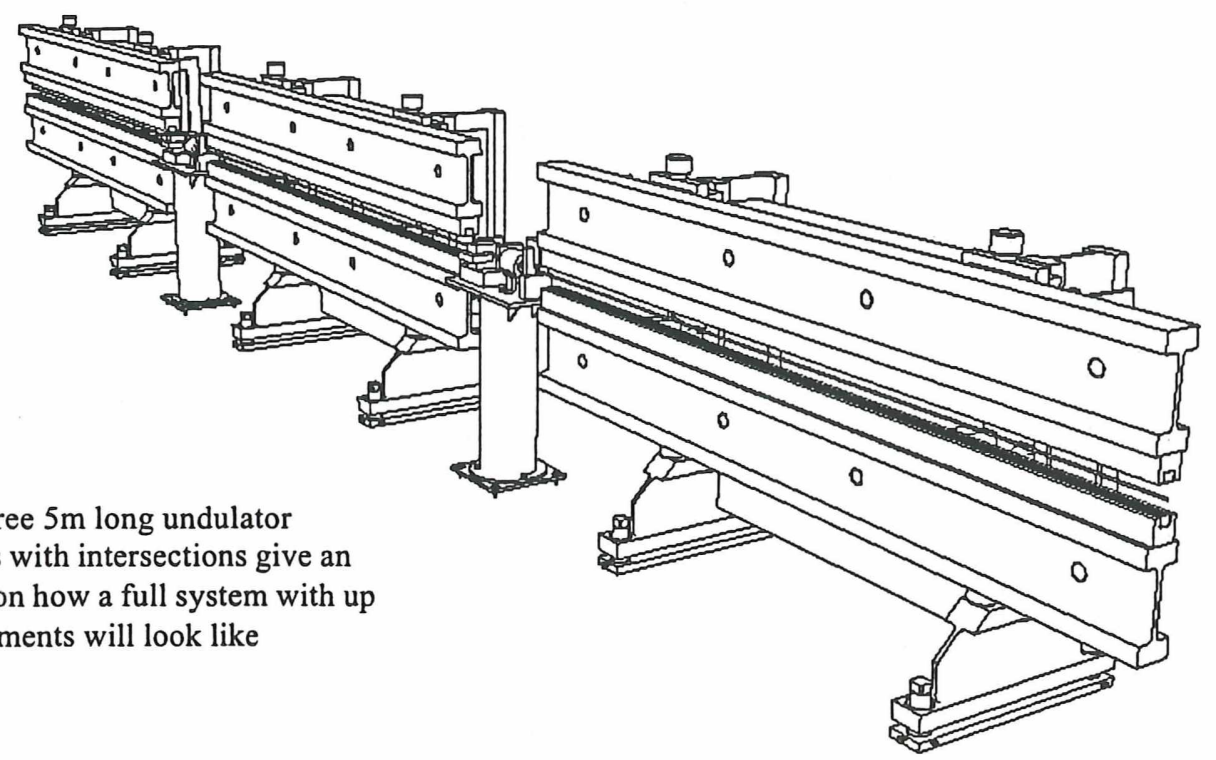

Fig1. Three $5 \mathrm{~m}$ long undulator segments with intersections give an impression how a full system with up to 54 segments will look like 
Table 1: Overview over the devices planned for the TESLA X-FEL (October 2000)

\begin{tabular}{|c|c|c|c|c|c|c|c|c|c|c|c|c|c|c|}
\hline Device & Type & \begin{tabular}{|l|}
$\mathbf{E}$ \\
{$[\mathrm{GeV}]$}
\end{tabular} & $\begin{array}{l}\text { Wavelength } \\
\text { Range [nm] }\end{array}$ & $\begin{array}{c}\text { Photon Energy } \\
{[\mathrm{KeV}]}\end{array}$ & $\begin{array}{c}\lambda_{0} \\
{[\mathrm{~mm}} \\
]\end{array}$ & $\rho_{\left[10^{4-}\right]}^{*}$ & $\mathbf{K}_{\text {Min }} / \mathbf{K}_{\mathbf{M a x}}$ & $\begin{array}{c}\mathrm{B}_{\operatorname{Min}} / \mathrm{B}_{\mathrm{Max}} \\
{[\mathrm{T}]}\end{array}$ & $\begin{array}{c}\mathrm{Gap}_{\text {Min }} / \mathrm{Gap}_{\text {Max }} \\
{[\mathrm{mm}]}\end{array}$ & $\beta[\mathrm{m}]$ & $\begin{array}{c}\text { Lsat + } \\
{[\mathrm{m}]}\end{array}$ & \begin{tabular}{|l}
$\mathbf{L}_{\text {Tot +H }}$ \\
{$[\mathrm{m}]$}
\end{tabular} & $\begin{array}{l}\mathrm{F}_{\mathrm{Mag}} \text { ** } \\
{[\mathrm{kN}]}\end{array}$ & $\begin{array}{l}\# \text { of Seg- } \\
4 \text { ments** } \\
*\end{array}$ \\
\hline SASE1 & planar & $\begin{array}{l}30 \\
25 \\
20 \\
\end{array}$ & $\begin{array}{l}0.1-0.25 \\
0.1-0.35 \\
0.15-0.50 \\
\end{array}$ & $\begin{array}{rr}12.4 & -4.9 \\
12.4 & -3.5 \\
8.25 & -2.5 \\
\end{array}$ & 60 & $\begin{array}{l}4.3 / 5.9 \\
4.2 / 6.3 \\
5.1 / 7.7 \\
\end{array}$ & $\begin{array}{l}4.6-7.5 \\
3.7-7.5 \\
3.7-7.0 \\
\end{array}$ & $\begin{array}{l}0.82-1.33 \\
0.66-1.33 \\
0.66-1,25 \\
\end{array}$ & $\begin{array}{l}19-12 \\
22-12 \\
22-13 \\
\end{array}$ & 45 & $\begin{array}{l}175 / 100 \\
220 / 120 \\
220 / 150 \\
\end{array}$ & 323.3 & $26.7 / 70.2$ & 53 \\
\hline SASE2 & planar & \begin{tabular}{|l|}
25 \\
20 \\
\end{tabular} & \begin{tabular}{|l|l|}
0.085 \\
0.13 \\
\end{tabular} & $\begin{array}{r} \\
14.6 \\
9.3 \\
\end{array}$ & 45 & $\begin{array}{l}3.6 \\
4.1 \\
\end{array}$ & $\begin{array}{l}4.0 \\
4.0 \\
\end{array}$ & $\begin{array}{l}0.95 \\
0.95\end{array}$ & $\begin{array}{l}- \\
12 \\
12 \\
\end{array}$ & $-\overline{45}$ & $\begin{array}{l}- \\
210 \\
155\end{array}$ & 311.1 & 35.8 & 51 \\
\hline SASE3 & planar & \begin{tabular}{|l|}
23 \\
15 \\
\end{tabular} & $\begin{array}{l}0.10 \\
0.24 \\
\end{array}$ & \begin{tabular}{r|}
12.4 \\
5.2 \\
\end{tabular} & 45 & \begin{tabular}{|l|}
3.8 \\
4.1 \\
\end{tabular} & $\begin{array}{l}4.0 \\
4.0 \\
\end{array}$ & $\begin{array}{l}0.95 \\
0.95\end{array}$ & $\begin{array}{l}12 \\
12 \\
\end{array}$ & 45 & $\begin{array}{l}185 \\
115 \\
\end{array}$ & 274.5 & 35.8 & 45 \\
\hline SASE4 & planar & \begin{tabular}{|l|}
25 \\
15 \\
\end{tabular} & \begin{tabular}{|l|}
$0.1-0.35$ \\
$0.3-1.0$ \\
\end{tabular} & $\begin{array}{l}12.4-3.5 \\
4.1-1.24 \\
\end{array}$ & 60 & $\begin{array}{l}4.2 / 6.3 \\
7.1 / 10.3 \\
\end{array}$ & \begin{tabular}{|l|}
$3.7-7.5$ \\
$3.9-7.5$ \\
\end{tabular} & $\begin{array}{l}0.66-1.33 \\
0.70-1.33 \\
\end{array}$ & \begin{tabular}{|l|}
$22-12$ \\
$21-12$ \\
\end{tabular} & 45 & $\begin{array}{l}220 / 120 \\
125 / 80 \\
\end{array}$ & 323.3 & $26.7 / 70.2$ & 53 \\
\hline SASE5 & helical & \begin{tabular}{|l|}
23 \\
15 \\
\end{tabular} & \begin{tabular}{|l|}
$0.4-2.5$ \\
$1.0-5.8$ \\
\end{tabular} & $\begin{array}{ll}3.1-0.5 \\
1.25-0.21 \\
\end{array}$ & 107 & $\begin{array}{l}14.5 / 26.8 \\
19.2 / 35.7 \\
\end{array}$ & \begin{tabular}{|l|}
$3.8-9.6$ \\
$3.9-9.6$ \\
\end{tabular} & $\begin{array}{l}0.38-0.96 \\
0.39-0.96 \\
\end{array}$ & \begin{tabular}{|l|}
$35-12$ \\
$35-12$ \\
\end{tabular} & 15 & \begin{tabular}{|l|}
$120 / 60$ \\
$95 / 50$ \\
\end{tabular} & 176.9 & $11.5 / 73.2$ & 29 \\
\hline U1-U5 & planar & $\begin{array}{l}30 \\
15\end{array}$ & $\begin{array}{l}0.0083-0.025 \\
0.0028-0.0083 \\
0.033-0.10 \\
0.0123-0.033\end{array}$ & $\begin{array}{l}\text { 150-50 1. Harm } \\
450-150 \text { 3.Harm } \\
37-12 \text { 1. Harm } \\
111-37 \text { 3. Harm }\end{array}$ & 30 & --- & $0 .-3.1$ & 0. -1.10 & up-(13)-6 & 45 & $\begin{array}{l}50.0+++ \\
250 \text { total }\end{array}$ & $\begin{array}{l}61.0 \\
305 \text { total }\end{array}$ & $51.6 \max$ & $\begin{array}{l}10 \\
50 \text { total }\end{array}$ \\
\hline
\end{tabular}

$+\quad$ The saturation length is taken as the net magnetic length of the undulator

++ The total length of an undulator system includes the saturation length plus $1.1 \mathrm{~m}$ for intersections (Quadrupoles, phase shifters, correctors, diagnostics pumps etc) and $20 \%$ contingency for field errors, misalignment etc. For the spontaneous radiators no contingency for the device length is considered.

++ For the spontaneous radiators U1-U5, the "saturation length" represents the assumed magnetic length of each device. The summation in the bottom line includes 5 devices

* For SASE1-4 a normalized emittance $\varepsilon_{\mathrm{n}}$ of $1.6^{*} 10^{-6} \mathrm{~m}$, an energy spread of $2.5 \mathrm{MeV}$ and a peak current of $5000 \mathrm{~A}$ is used. For SASE5 due to the spent beam an energy spread of $6.0 \mathrm{MeV}$ is used.

** A pole width of $40 \mathrm{~mm}$ and a undulator segment length of $5.0 \mathrm{~m}$ is assumed. Load values for max. / min gaps are given.

The total magnetic length including $20 \%$ contingency is $1405 \mathrm{~m}$, the total undulator length, intersection inclusive is $1714.1 \mathrm{~m}$

*** Length assumptions: Undulator segment : $5.0 \mathrm{~m}$; Intersection : $1.1 \mathrm{~m}$; resulting cell length : $6.1 \mathrm{~m}$; 


\section{Hardware Setup}

\section{Overview}

Fig. 1 has already shown an overview. Each of the undulator segments is $5 \mathrm{~m}$ long. In the intersections several components are needed such as phase shifters, quadrupoles, correctors, beam position monitors etc.. Altogether an intersection is $1.1 \mathrm{~m}$ long. Table 1 shows that an undulator system may be composed by up to 54 cells so that the total length becomes about $312 \mathrm{~m}$. For the whole FEL laboratory the total length of the undulator systems is $1714 \mathrm{~m}$.

The segmentation shown in Fig.1 is needed to keep the beam size small over the whole length. To do so a so-called FODO lattice, a sequence of focusing and defocusing quadrupoles is needed. The distance between two of them is $6.1 \mathrm{~m}$ and provides enough space so that $5 \mathrm{~m}$ long undulator segments can be installed. The average $\beta$-function in most undulator sections has been chosen to be $45 \mathrm{~m}$ (see table 1).

Wavelength tunability, i.e. gap tuning is required for three of the SASE undulators and the spontaneous radiators as well. This has two consequences: First, in the case of SASE undulators the saturation length is increased because the shortest wavelength at which the FEL is to operate is at the upper gap of the tunability range and determines the saturation length. Second, the matching of the phase of the photon beam between different segments becomes gap dependent. This situation is completely different as compared to the Tesla Test Facility, where the gap is fixed and proper phasing is most easily done by a correct choice of the distance between individual undulator segments. If the undulator gap and therefore the radiation wavelength is changed the interference condition is changed too. Changing the inter-segment distance is completely impractical in an undulator system with a large number of segments. Instead, the electron beam has to be slightly delayed as compared to the photon beam. This is done by a suitably designed magnetic chicane a so called a phase shifter(see below). In addition one beam position monitors (BPM's) and one beam correctors are required near each FODO quadrupole.

\section{Standardization}

It was already mentioned, that the undulator system for a X-ray FEL is a long repetitive array of undulator cells. There will be a large number of identical items. This calls for standardization. Ideal candidates are :

1. The gap separation drive systems, motion control components, motors, servos etc.

2. Girders

3. Components inside the undulator interruptions such as phase shifters, corrector magnets and their power supplies, quadrupoles and beam position monitors (BPM's).

4. Control system for gap motion and gap dependent excitation of coils, readout of BPM's etc.

5. Vacuum chambers and other vacuum equipment

These components should be designed according to worst case assumptions. For example mechanical gap separation drive systems and girders should be designed for maximum magnetic forces and worst case assumptions on mechanical deformation. It is of little use design different gap separation systems only because the mechanical load conditions are slightly different. In a similar fashion phase shifters should be designed to meet the phase shifting requirements at the longest wavelength. The small increase in cost for over designing components is usually overcompensated by reduced construction effort, by simplified production with larger numbers and later in the operation phase by simplified maintenance and spare part supply.

\section{Description of an undulator system \\ Mechanical design}

A standard gap separation drive and support system has been developed in a conceptual design study 14/. It considers the principles of economic manufacturing of large quantities, while tough

requirements on mechanical accuracy have to be maintained. The 3D view in Fig. 2 shows how these ideas could be realized. For the girders a voluminous I-beam profile with dimensions $550 * 200 * 100$ $\mathrm{mm}$ is used. In order to avoid girder deformation under changing load conditions (gap change) larger than $\pm 4 \mu \mathrm{m}$ such a large girder profile with a corresponding large moment of inertia and a four point support is needed. The same profile is also used for the support columns and the floor stands. This is 


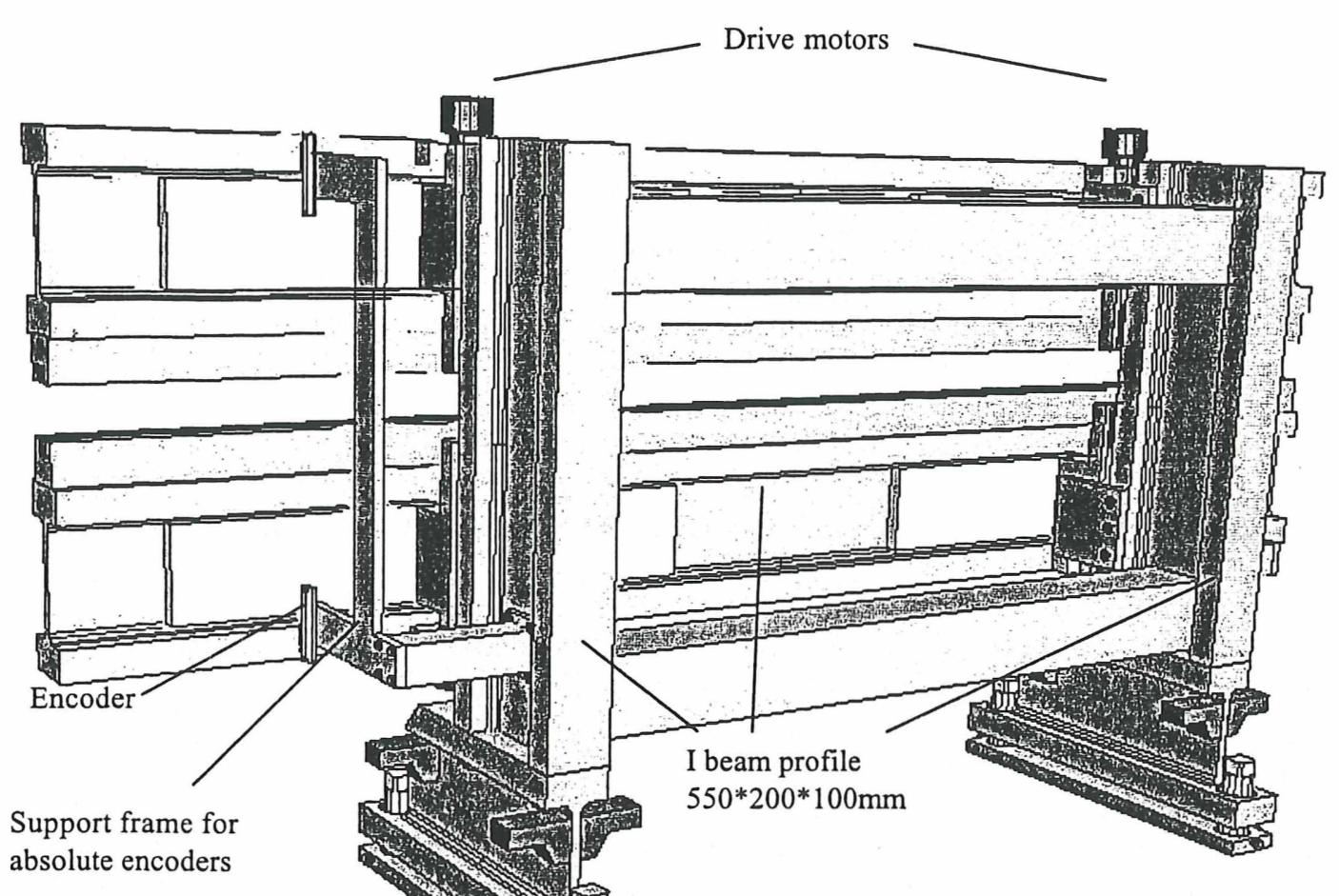

Support frame for absolute encoders

Fig.2 Standard undulator segment for the TESLA undulator systems

much simpler to build than a welded structure and has the same or even improved stability. This large profile cannot be ordered off the shelf. It has to be produced on special request by a steel mill. This is unproblematic since more than $4700 \mathrm{~m}$ of this profile with a total weight of 1900 tons will be needed for the 281 support systems. Only little machining is required on the columns. Standard guiding elements are used. There are four individual motors which are appropriately synchronized by a control unit. Motors and their motion control units are part of the control system $/ 5 /$. In order to get gap

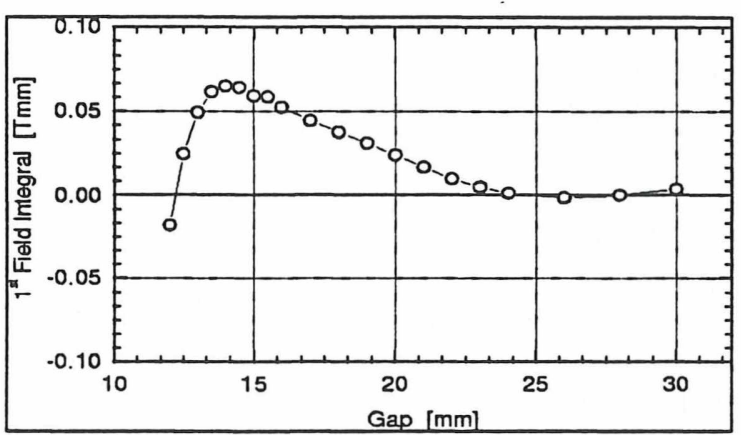

Fig. $31^{\text {st }}$ Field integral as a function of the gap for the optimized prototype structure information with micrometer accuracy separate frames are used to support absolute length encoders. In this way the exact girder position close to the motor can be measured without errors induced by deformation of the girder support or the support structure. Gap adjustment accuracy is better than $\pm 2 \mu \mathrm{m}$.

\section{Linear Magnetic structure}

A planar magnet design based on $\mathrm{NdFeB} \mathrm{PM}$ hybrid technology has been developed for a prototype structure for the SASE1 undulator /6/. Its parameters are consistent with those given in table 1. At a gap of $12 \mathrm{~mm}$ and a period length of $60 \mathrm{~mm}$ the peak field is $1.33 \mathrm{~T}$. At $25 \mathrm{GeV}$ and a gap of $22 \mathrm{~mm}$ this device would

radiate at $0.1 \mathrm{~nm}$ and at $12 \mathrm{~mm}$ gap at $0.35 \mathrm{~nm}$.

The width of poles and magnets was determined such that a transversal good-field-region of $\pm 1 \mathrm{~mm}$ results in which the relative field variation is less than the $\rho$-parameter, i.e. $4.2 \cdot 10^{-4}$ in the open gap position. This is the most restricting case. In this way horizontal alignment requirements on the undulator segments are reduced and the FEL process is not affected by poor field homogeneity. Thus the proportions of magnets and poles have been optimized in terms of a sufficiently wide good-fieldregion and simultaneously, the required magnet volume has been minimized. The maximum peak field is obtained for a pole length of about $8 \mathrm{~mm}$. The iterative optimization results in a pole geometry of 
$40 \times 8 \times 55 \mathrm{~mm}^{3}$ (width $\times$ length $\times$ height) and $70 \times 22 \times 65 \mathrm{~mm}^{3}$ for magnets. This corresponds to a magnet volume of $400 \mathrm{~cm}^{3}$ per period or a demand for 13.3 tons magnet material for the 53 segments of $5 \mathrm{~m}$ length.

The end pole configuration of multi-segmented devices is a critical issue in the magnetic design. Residual field integrals should be compensated for all gaps as good as possible preferably by appropriate passive elements. The undulator segment is designed in a symmetric way so that the $2^{\text {nd }}$ field integral cancels once the $1^{\text {st }}$ field integral is tuned to zero. The length and vertical position of the last magnet, the height of the last pole as well as the width of the $2^{\text {nd }}$ last pole are used to tune the $1^{\text {st }}$ field integral. Fig. 3 shows the calculated residual gap dependence of the $1^{\text {st }}$ field integral. A maximum residual field integral of $0.05 \mathrm{Tmm}$ is induced at $13 \mathrm{~mm}$ gap while for short photon wave lengths, i.e. large gaps, a value $<0.005 \mathrm{Tmm}$ is achieved. The remaining gap dependence can be compensated by means of shims which so far have not been included in the calculation. Also more sophisticated solutions in the end pole optimization including a modification of the pole shape will be elaborated in the future. A straight forward solution using active correctors will be foreseen in any case. (see below).

\section{Planar helical magnetic structure}

For SASE 5 a helical structure is planned. There are two criteria which have to be fulfilled:

1. The structure should be planar thus allowing lateral access for high precision magnetic characterization and the insertion of vacuum systems.

2. Polarization properties should be adjustable

A Sasaki-type undulator is proposed, which fulfills these requirements in an ideal way $/ 7 /$. In addition this type of magnet structure offers the highest fields and greatest variation of polarization characteristics found in literature. Fig.4 shows the working principle of this structure. It is based on a pure permanent magnet structure which is sliced along the electron beam axis in four parts: Upper Front/Back and Lower Front/Back. The Upper Back and Lower Front are kept fixed. The Upper Front and Lower Back can be moved along the beam axis by an amount $D$, which is limited to $\pm \lambda_{0} / 4$. For $\mathrm{D}=0$ the structure is a equivalent to a standard pure $\mathrm{PM}$ structure producing linear polarized light. If

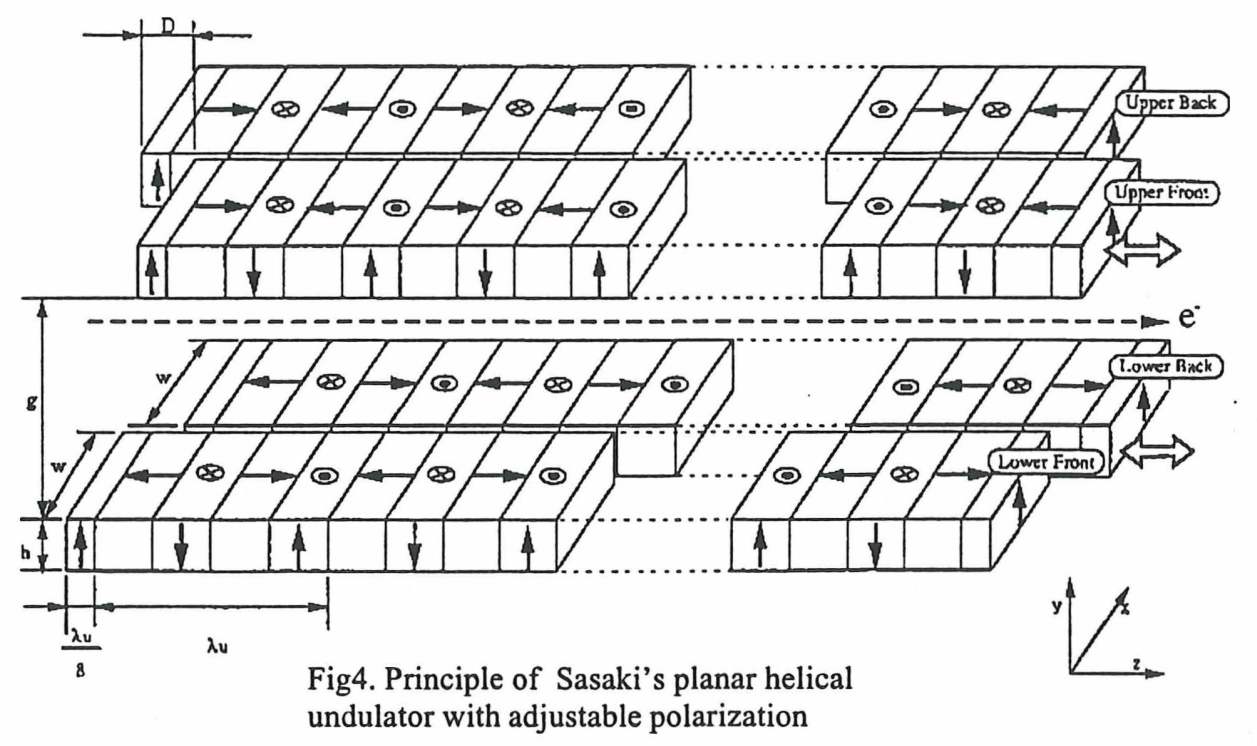

$D= \pm \lambda_{0} / 4$ and Upper Front and Lower Back are moved parallel (moved in the same direction) then, right/left handed circular polarized light is produced. In between there is elliptical polarization. If Upper Front and Lower Back are moved anti-parallel (moved in opposite directions) linear polarized light with an inclined plane of polarization is produced. Two additional independent drive systems are required to shift the Upper Front and Lower Back girder. The switching rate is slow, typically it takes several seconds to go from right to left polarization.

At BESSY II several of these devices are in operation or under construction. They are up to $3.2 \mathrm{~m}$ long. A comprehensive experimental study of their magnetic as well as the optical emission properties has 
been published for these devices/8/. A preliminary design study based on this work for a Sasaki type undulator for SASE5 at TESLA has been made by Bahrdt et al. /9/. There, the polarization properties are explained in detail.

A Sasaki type undulator with adjustable properties requires considerable more mechanical effort than a planar one. Effectively one half of the structure needs to be shifted and has to be equipped with suitable drives.In the case of SASE5 $120 \mathrm{~m}$. It is a pure permanent magnet structure. No soft iron must be used for the girders. So its magnetic field quality depends completely on the quality of the permanent magnet material only. Great care is needed in the characterization and selection of the magnets. Also iron parts for the support beams have to be avoided. However, the experience at BESSYII is very encouraging. The mechanical effort became evident and it has been demonstrated that such a device can be built with very good quality. It serves as a basis for the extrapolation to the $177 \mathrm{~m}$ long SASE5 undulator system for TESLA.

\section{Gap tunability, Phase matching, Beam Correctors}

For three of the SASE undulators and the spontaneous radiators tunable wavelengths by means of gap tuning is required. This has three consequences:

1. In the case of the SASE undulators the saturation length is increased because the shortest wavelength at which the FEL is to operate is at the upper gap and determines the system length.

2. The phase matching of photon beam originating from different segments becomes gap dependent. This relates likewise to the SASE and spontaneous devices as well. A phase shifter consisting of a three magnet chicane is needed. A phase shifter with sufficient strength has been designed for the for the TESLA undulators. It is described in more detail in ref. /10/.

3. The third complication relates to field errors. In a tunable undulator gap dependent errors might occur. For example field integral errors, which might be fully compensated at one specific gap only. Especially in hybrid structures this may happen. This residual errors are expected to be very small. The most straight forward solution is to use corrector coil with a gap dependent current setting.

For horizontal correction one of the chicane magnets can simultaneously be used. The same type of magnet, rotated by $90^{\circ}$ is used to steer the beam vertically. The corrector magnets have a double function:

1. They have to provide correction for quadrupole misalignment and the Beam Based Alignment technique This correction is gap independent.

2. They eventually have to make a small gap dependent correction as described above, which is due to undulator errors as described above.

Fig 5 shows a 3D view of an undulator intersection embedded between two neighboring undulator segments. The phase shifter is seen to the left. It consists of three horizontal magnets. The length of the center one is doubled because it needs twice the strength. The vertical corrector is seen to the right. In between there is a quadrupole with a $15 \mathrm{~mm}$ bore which is capable of producing a maximum gradient of $100 \mathrm{~T} / \mathrm{m}$. Its magnetic length is $0.2 \mathrm{~m}$ only, the total length is about $0.26 \mathrm{~m}$. With these quadrupoles a minimum $\beta$ function of less then $15 \mathrm{~m}$ at $25 \mathrm{GeV}$ can be obtained without problems. Although SASE2 and SASE3 are operated at a fixed gap, they should also be gap adjustable too. There are good reasons to do so:

1. The radiation wavelengths of different segments have to be tuned with an accuracy better than the $\rho$ parameter, which is in the order of $2.10^{-4}$ (see table 1). As a consequence in different segments gap control with an accuracy of : $\Delta g<\approx \pm 2 \mu \mathrm{m}$ is needed. This accuracy cannot be obtained in a truly fixed gap device. Although the field might be precisely adjusted in the lab it is not preserved on this level of accuracy. So some adjustment has to be provided anyhow.

2. In order to compensate for the average energy loss of the electron beam along the undulator system, a taper has to be applied. It increases efficiency and maximizes the output intensity. Such a taper will be effectively a step taper, the gap will be changed in very fine steps from one segment to the next:

3. A segment it can effectively be switched off by fully opening its gap. In this way the effective length of the undulator system can be varied. For diagnostic reasons this option might become very important. In ref $/ 1 /$ a 'photon beam based' alignment procedure is described. Starting at the entrance the spontaneous radiation emitted by each segment, one by one, is detected in a diagnostic station downstream in the photon beam line. The electron beam may be steered such 
that all the radiation spots overlap completely. The beam is threaded through the undulator system in this way. The proper phasing between undulator segments can also be checked in this way.

4. Experience at TTF has shown that high radiation levels may be created if the beam is miss-steered. Although this must not occur during routine operation it nevertheless might happen during machine setup or commissioning of the machine. The maximum gap to which the TESLA undulators can be opened is $200 \mathrm{~mm}$. This would eliminate the radiation hazard to the magnetic structure.

In a fixed gap device without taper like the undulator for the TTF phase shifters are not needed. At TESLA it might be useful to fine adjust the phasing in the tapered sections. For this reason the phase shifters should be included. The additional expenses are moderate. One of the phase shifting magnets is needed for horizontal correction anyhow so that only two magnets plus one power supply are needed additionally.

\section{Alignment}

The great advantage of separating undulator and focusing in the TESLA undulators systems is that there are only moderated requirements on the alignment of the undulator segments $/ 11$. Provided that the fields and field integrals of individual segments are well tuned and adjusted they behave almost like drift spaces to the $15-50 \mathrm{GeV}$ e-beam. For obtaining good overlap between electron and photon beam the quadrupoles play the dominant role. They need very stable supports. Their centers have to be adjusted better than $20 \%$ of and RMS beam size or $\leq 4-5 \mu \mathrm{m}$ in both directions over the full length of an undulator system.

It is way beyond the capability of even the most sophisticated alignment techniques to obtain such an accuracy over the length of $200-300 \mathrm{~m}$. Also there is no way to measure and align the magnetic centers of the quadrupoles with this accuracy. As an alternative the method of beam based alignments (BBA) has to be used, which was originally developed for the final focus test beam at the Stanford Linear Collider. Two steps are needed: The will be a pre alignment with conventional optical techniques to

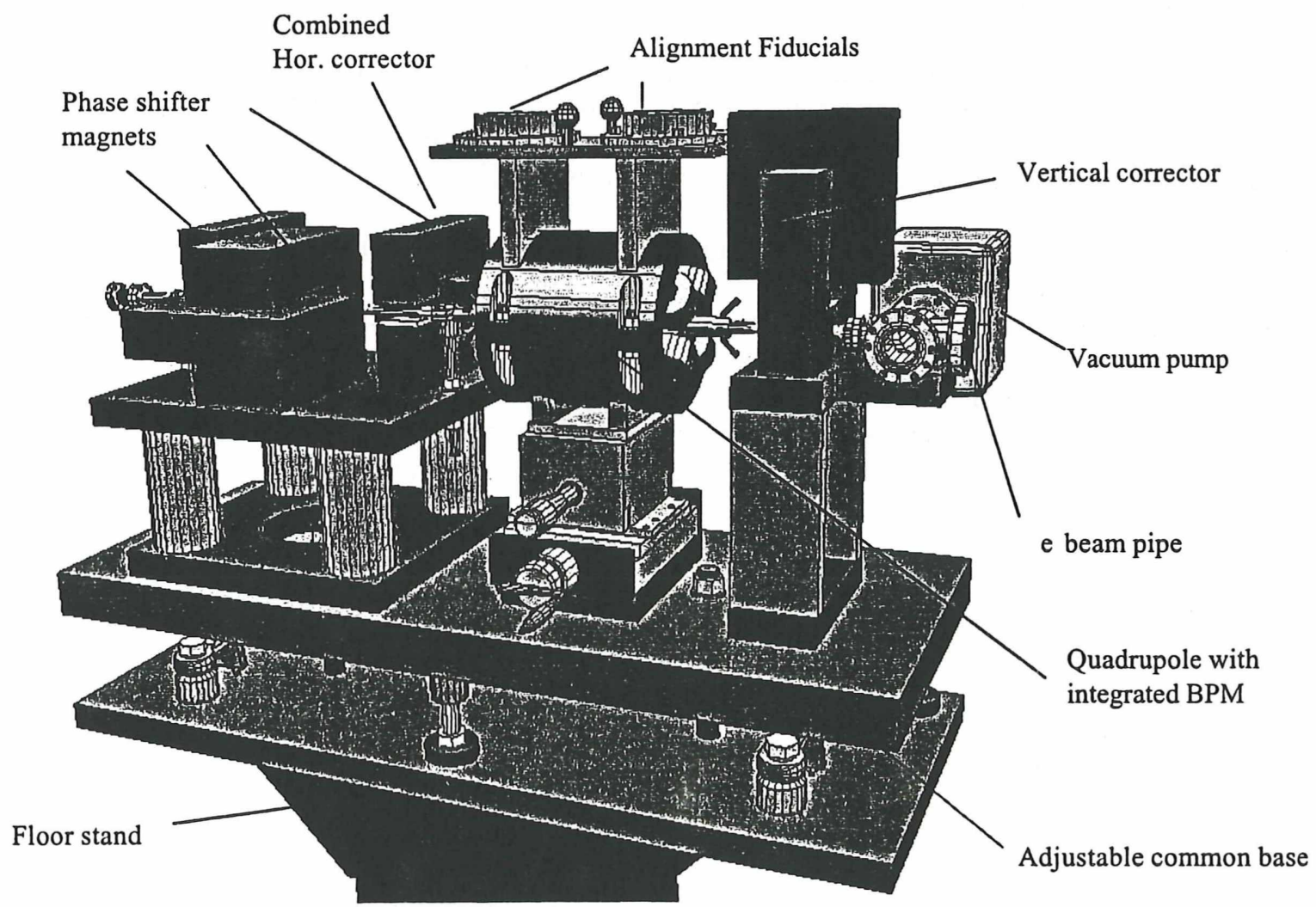

Fig. 5 Components in the intersection between undulator segments 
about $\pm 0.3 \mathrm{~mm}$ using Taylor-Hobson spheres placed on the fiducial fixtures and the horizontal / vertical precision adjustments, which can be seen in Fig. 5. Fine alignment is done using BBA in conjunction with the horizontal and vertical corrector magnets in the intersections. Their strength is sufficient to compensate for a quadrupole misalignment of about $\pm 0.4 \mathrm{~mm}$. To correct this error in a $0.2 \mathrm{~m}$ long quadrupole with a gradient of $100 \mathrm{~T} / \mathrm{m}$ a corrector field integral of $\pm 0.008 \mathrm{Tm}$ is required. This is well within the capacity of the magnets used for the phase shifters.

\section{Control system}

Each undulator system needs its own control system. It has to do the following tasks:

- synchronize the motors for gap motion

- provide gap dependent current settings for phase shifters and corrector magnets.

- provide full computer control of the undulator system

- provide great flexibility to allow for numerous special operation modes

Most efficiently the control system is also organized in a cellular way in analogy to the mechanical setup. In this way it can be easily extended in a modular fashion. The control system of each cell consists of the four drive motors for the gap separation system and related components such as encoders, switches etc. which are needed for an undulator segment. The corrector coils of that segment which in general need current settings depending on the actual gap value of that segment also belong to that cell. Each cell is an individual unit and an undulator system is a repetitive array of 54 cells. A study for the realization of such a control system using industrial SIMATIC components has been made $/ 5 /$. It allows great flexibility and is an open system for future extensions.

\section{Industrial manufacturing}

The real challenge will be the manufacturing of 281 undulator segments in a reasonable time at sufficient quality and at reasonable cost This problem cannot and should not be solved at TESLA alone. A close collaboration with industry will therefore be of paramount importance in this context. In many SR Labs large parts or even complete undulators have already been built in industry. For example at HASYLAB encouraging experience exists for the undulators for DORISIII, PETRA and the FEL at TESLA Test Facility. Up to now, however, the critical part, i.e. the final assembly, the magnetic measurements and the magnetic fine tuning has been done in house since it requires expensive equipment and specialized staff. Other labs have developed similar ways to build Insertion Devices. Based on the existing good experience with this way of manufacturing, it is straight forward to extend the production to obtain "turnkey ready" devices for TESLA. For this goal a scenario has been developed.

The whole production process for 281 undulator segments is estimated to take 10 years after official project start.

5 years will be needed for extended R\&D phase to thoroughly prepare the production phase, which will take another 5 years. The R\&D phase will include:

- Improvement of the manufacturing process, magnet material and its quality $/ 12$.

- Development of reliable magnetic measurement techniques for use in industrial environment

- Design optimization and streamlining for large scale production including:

magnetic design

mechanical design

control / motion control

phase shifter

- Vacuum components

- Heavy prototyping including:

mechanical support system

control and motion control system

magnetic assembling, manufacturing, measurement and optimization techniques

- Planing and design of production capacities

After the R\&D phase everything will be ready for the subsequent production phase which will take another 5 years. Approximately one year is planned to set up the production capacities and the 
remaining 4 years are for "pure" production. An average production rate of at least six complete undulator cells per month including the components for the interspacing over the four years is required. The bottleneck in the production are the magnetic structures. They are the most expensive items in an undulator system and require most effort. Considerations on the size of a production plant for magnetic structures with the required capacity has been made in ref $/ 12 /$.

\section{References}

1. P. Elleaume, J. Chavanne, B. Faatz, "Design considerations for a 1 Angstroem SASE undulator at TESLA" TESLA-FEL 2000-16, and in press at Nucl. Instr. Meth.

2. E. Saldin, E. Schneidmiller, M. Yurkov to be published

3. Hasylab Annual Report 1999, p 103 ff

4. M. Rüter, J. Pflüger "A prototype gap separation system for the TESLA undulator" TESLA-FEL 2000-07

5. H. H. Radszuweit, J. Krunkowski, J. Pflüger, M. Tischer " Ein SIMATIC basiertes Kontrollsystem für die Undulatoren des TESLA Röntgenlasers" TESLA-FEL 2000-09, in german

6. M. Tischer, J. Pflüger "Magnetic design of a prototype structure for the X-ray FEL's at TESLA" TESLA-FEL 2000-12

7. S. Sasaki, Nucl. Instr. and Methods A347 (1991) 719

8. J. Bahrdt, W. Frentrup, A. Gaupp, M. Scheer, W. Gudat, G. Ingold, S. Sasaki "Elliptically polarizing insertion devices at BESSYII" Proceedings of the SRI2000, Aug 21-25 2000, Berlin, Germany

9. J. Bahrdt, A. Gaupp, U. Englisch, W. Frentrup, M. Scheer, "Conceptual Design of a planar helical undulator for the TESLA SASE FEL", TESLA-FEL 2000-11

10. J. Pflüger "A prototype phase shifter for the undulator systems at the TESLA X-ray FEL" TESLA-FEL 2000-08

11. J. Pflüger,'Undulators for SASE FEL's", Nucl. Instr. and Methods A445, (2000) 366

12. R. Cremer, F. J. Boergemann, J. Pflueger, M. Tischer " Manufacturing Considerations of the magnetic structures of the undulators for the X-FEL at TESLA", TESLA-FEL 2000-10 


\section{Stand der TESLA-Planung}

TESLA · Ein supraleitender Linear Collider mit integrierten Röntgenlasern und ein neues interdisziplinäres Forschungszentrum in Ellerhoop

Wilhelm Bialowons, DESY · MPY, Hamburg

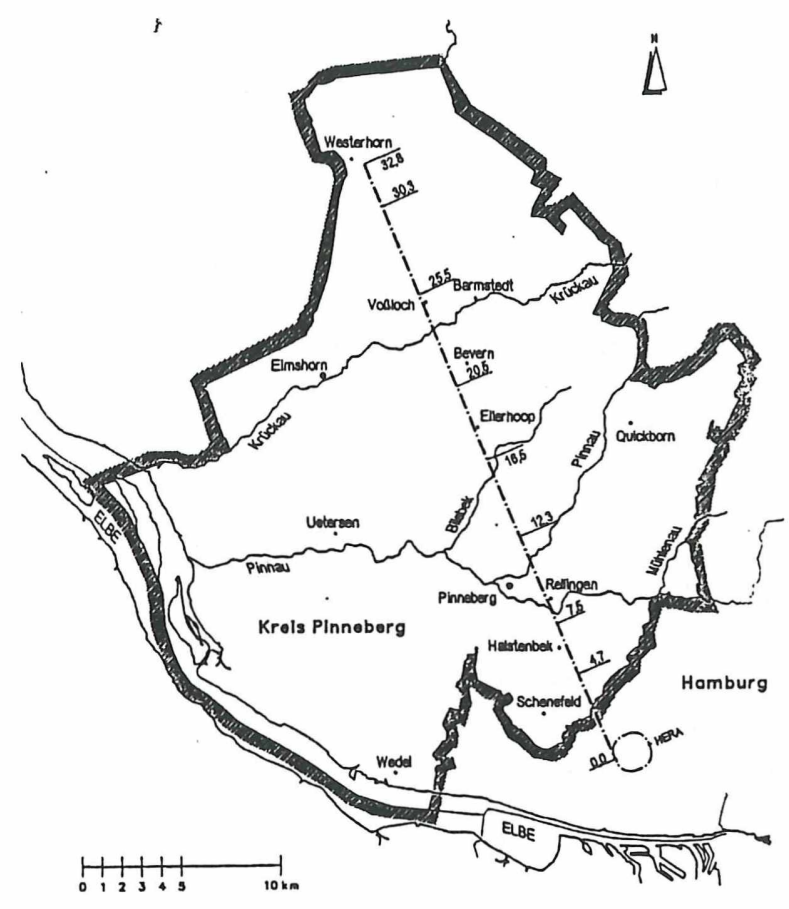

Abbildung 1: Lageplan des Linear Collider Tunnels in Hamburg und im Kreis Pinneberg.

\section{PROLOG}

Das Deutsche Elektronen-Synchrotron DESY plant im Rahmen einer internationalen Zusammenarbeit den Bau der Forschungsanlage TESLA [1]. Sie besteht im wesentlichen aus einem etwa $33 \mathrm{~km}$ langen Tunnel. Er beginnt auf dem DESY-Gelände in Hamburg-Bahrenfeld und verläuft in Richtung Nordnordwest durch den Kreis Pinneberg bis zur Gemeinde Westerhorn (siehe Abbildung 1). Der Tunnel liegt also in der Freien und Hansestadt Hamburg und dem Land Schleswig-Holstein. Die beiden Bundesländer haben einen Staatsvertrag für die Schaffung der planerischen Voraussetzung für die Errichtung und den Betrieb von TESLA abgeschlossen, um eine Rechtsgrundlage zu schaffen. Damit braucht nur ein Zulassungsverfahren durchgeführt werden. Als Folge des Staatsvertrages ist DESY als Träger öffentlicher Belange im Kreis Pinneberg eingetragen worden. Damit haben wir das Recht bekommen, Einfluss auf neue Bauleitplanungen zu nehmen. DESY lässt die TESLA-Trasse, die Lage der oberirdischen Hallen und Vorbehalte aus dem Staatsvertrag in die neuen Pläne eintragen. Dadurch werden die betroffenen Gemeinden verstärkt auf TESLA aufmerksam gemacht. Um den damit auch verbunden Informationsbedarf der Bürger zu stillen, wird DESY zu Einwohnerversammlungen eingeladen. Über diese öffentlichen Veranstaltungen berichtet die lokale Presse. Eini- ge provokative Artikel, auf die hier auch eingegangen wird, haben die Anregung zu diesem Vortrag gegeben.

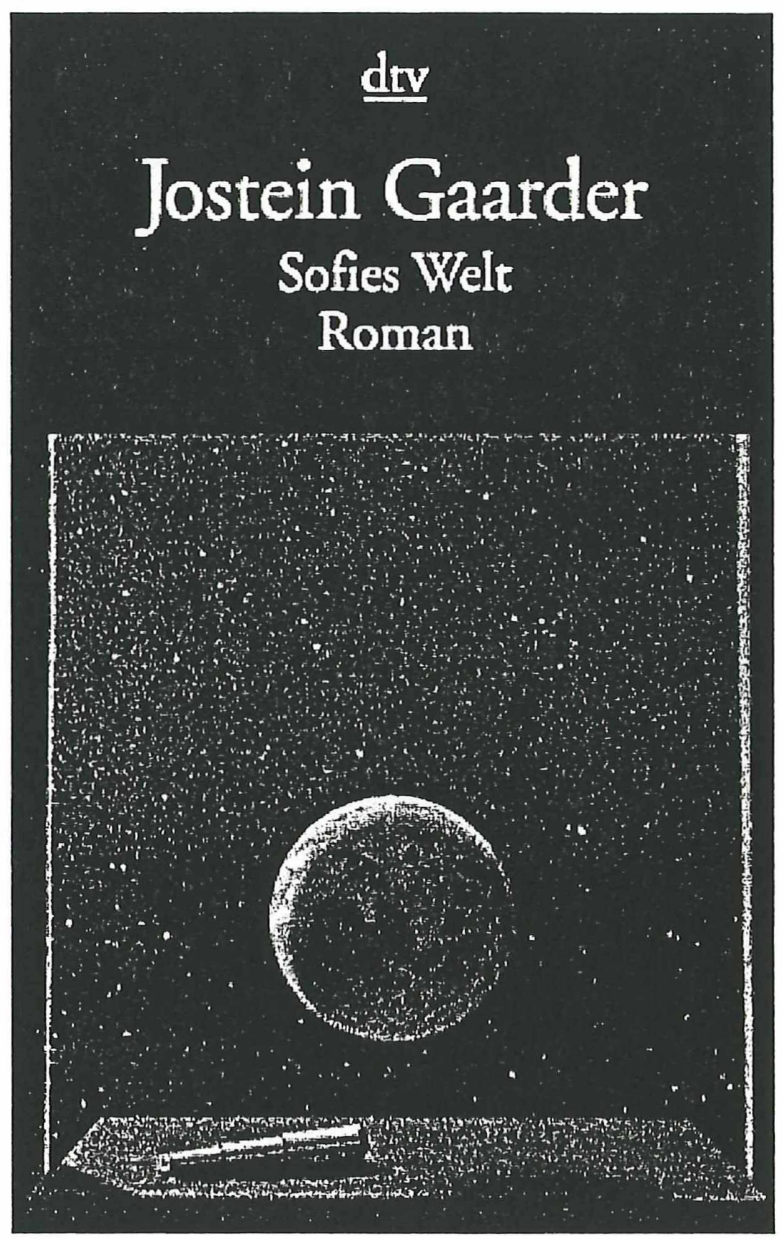

Abbildung 2: Der Garten Eden ${ }^{1}$.

... schließlich und endlich musste doch irgendwann etwas aus null und nichts entstanden sein ...

\section{EINLEITUNG}

Auf den Einwohnerversammlungen interessieren sich die Bürger häufig nur für die Lage des Tunnels und der Hallen. Sie sind meistens erst dann zufrieden, wenn sie ihr eigenes Haus in Bezug auf TESLA entdeckt haben. Trotzdem versuchen wir immer wieder, die Zuhörer an den Sinn der Hochenergiephysik heranzuführen. Das erste Mal konnte ich die Teilnehmer fesseln, als ich eine Parallele zu der Schöpfungsgeschichte gezogen habe. Eine weitere Anregung kann man in einem norwegischen Roman entdecken.

\footnotetext{
${ }^{1}$ Jostein Gaarder $\cdot$ Sofies Welt $\cdot$ Roman $\cdot \underline{\text { dtv }} 12555$
} 